\title{
NON-DESTRUCTIVE TESTING OF DISSIMILAR WELDED JOINTS
}

\author{
Maria-Cristina DIJMĂRESCU \\ Politehnica University of Bucharest, Romania \\ e-mail: maria.dijmarescu@upb.ro
}

\begin{abstract}
This paper presents research's results of non-destructive examination of dissimilar welded samples. The samples were made using sheets of austenitic stainless steel and carbon steel welded through the method of MAG welding with tubular wire. The samples were subjected to non-destructive testing in order to analyse the integrity of the welded seam, heat affected zone and the adjacent area of the weld.
\end{abstract}

KEYWORDS: non-destructive testing, austenitic stainless steel, carbon steel, dissimilar welded join, MAG welding

\section{Introduction}

Quality assessment can be put into practice by knowing the quality characteristics that are linked to a system of indices, indicators and coefficients. The assessment is required by the complexity of products and processes, being able to synthetically express a number of aspects of quality $[1,2]$.

The quality inspection of welded joints is an extremely complex branch, with many methods, techniques, and analysis and evaluation tools available. In order to be able to understand and use the quality assessment methods, a study of the specialized terminology currently used in this field, a terminology to be used in this paper, was also carried out. Terminology have been defined as: welding, imperfection, etc. [2-4].

The inspection methods for welded joints were presented and their classification in the three categories - the production process, the integrity of the product under examination and the number of products checked [4].

The imperfections of welded joints represent any deviation from shape, size, continuity, structure, appearance, composition or properties prescribed for a particular seam in the technological documentation. These have the effect of reducing resistance and worsening behavior in the exploitation of a welded joint. $[5,6]$.

Because the nonconformities can affect the performance and longevity of welded joints, early detection and correction is essential to ensure that the welded structures meet their designing purpose. After detecting the nonconformities in welded joints, an assessment should be made to determine their severity and the appropriate measures to be taken. Even the hardest to detected imperfection may encounter an inadequate welded structure to achieve its intended purpose [6, 7].

Detection techniques must be sensitive enough to detect dangerous discontinuities. It is necessary to repair the defects that damage the structural integrity of the welded joint. Welds do not have to be perfect; they must be within the permissible work limits specified in the quality standards used during the welded structure inspection $[4,6,7]$.

After analysing the specialty literature in order to highlight the welding processes used to obtain dissimilar welding joints the following processes were identified:

- gas metal arc welding, MIG/MAG, with normal and tubular wire [8-10];

- gas tungsten arc welding, WIG [11-13];

- friction welding [14];

- $\quad$ electron beam welding [15];

- fiber laser welding [16], etc.

The MIG/MAG process is the most used for manufacturing dissimilar joints and the combination between stainless steels and structural steels is widely used because of the economic benefits.

Examination of welded joints begins with the examination of the materials used in the welding process and ends with the final examination of the resulting joint. The final examination consists in checking the welded joint using different nondestructive methods. These methods are classified in two categories [17-19]: destructive and nondestructive examination.

The non-destructive examination methods used to examine the welded structure are chosen by taking 
into account the geometry of the part, the surface and the accessibility of the part to be examined.

The methods used to verify the structures are divided into two categories, and namely $[17,18]$ :

- Methods to highlight surface and near surface imperfections that are dependent on the surface area and accessibility to the examination. These include:

- Visual Testing (VT) - used to detect surface imperfections and also as an integrated part of the others non-destructive methods.

- Penetrant Testing (PT) - used to detect imperfections which are open to the surface of the tested material. It is applied on metallic materials, but also on non-metallic materials, e.g., ceramics.

- Magnetic Testing (MT) - used for the detection of surface imperfections and below the surface in ferromagnetic forgings, castings and welds including the heat affecting zones using the continuous Its sensitivity is reduced rapidly with the depth.

- Eddy Current Testing (ET) - used for the detection of surface breaking and near surface planar defects and it is applied on welds of almost any configuration.

- The methods used to identify inner imperfections are dependent on the geometric geometry of the part to be examined. Most commonly used are Ultrasound Testing (UT) and Radiographic Testing (RT), both used to detect inner and surface imperfections in welds. They can be applied on any type of material, taking into account the specific limitations for each method and the security norm for radiographic testing.

- In addition to the methods mentioned, the following method is also evaluated:

- leak Test (LT) - highlights fluid leaks.

- Infrared Thermography (TT) - allows the detection of defects in layered, coated, glued, composite materials; measuring the thickness of coatings or coatings; characterization of materials in terms of thermal behavior; evaluation of the structure of polymeric composite materials, analysis or measurement of the heat flux provided by the examined product (heat exists or is produced independently of the examination process).

- Acoustic Emission (AT)- allows monitoring the structures integrity, report losses through leakage, the early detection of cracks or even when they appear, characterizing the behavior of materials.

This paper presents the applications of different non-destructive methods in order to identify the imperfections in dissimilar welded joints. To achieve the proposed activities, the following steps were taken establishment of welding technology used for sample making, welded joints making, mechanical and chemical cleaning (degreasing) of samples, Visual Testing, Penetrant Testing, Ultrasound Testing, Radiographic Testing.

\section{Experimental data}

\subsection{Sample description}

At present, the joint between two dissimilar materials, steel carbon, S235JR + AR and a stainless steel austenitic, X2CrNiMo17-12-2, are often used, for this reason for making the experiments was chosen to perform a dissimilar welded joint.

Carbon steel and austenitic stainless steel were used as materials for the samples, the two steels being representative of the classes they belong to.

The experimental plan consists of the following steps: choice of the basic material, choice of the welding groove: type and geometry, choice of the welding process, selection of the filler material and execution of the welded joints.

The chemical composition and the mechanical proprieties of the base materials are presented in Table 1 and Table 2.

The selection of the filler material for making the dissimilar welded joint from the range of materials made available was done by means of an analysis. The analysis was made using the software Autodesk Inventor. This consisted of a series of stress and fatigue strength for the type of groove chosen at the previous point.

Table 1. Chemical composition of the base materials [20,21]

\begin{tabular}{cccccccccc}
\hline Chemical Composition & $\mathrm{C} \%$ & $\mathrm{Cr} \%$ & $\mathrm{Mn} \%$ & $\mathrm{Mo} \%$ & $\mathrm{~N} \%$ & $\mathrm{Ni} \%$ & $\mathrm{P} \%$ & $\mathrm{~S} \%$ & $\mathrm{Si} \%$ \\
\hline $\begin{array}{c}\text { X2CrNiMo17-12-2 } \\
\text { EN ISO 100088-3 }\end{array}$ & 0.03 & $16-18$ & 2 & $2-3$ & 0.10 & $10-14$ & 0.045 & 0.03 & 0.75 \\
\hline $\begin{array}{c}\text { S235JR + AR } \\
\text { EN10027-2 }\end{array}$ & 0.17 & - & 1.40 & - & 0.012 & - & 0.035 & 0.035 & - \\
\hline
\end{tabular}


THE ANNALS OF "DUNAREA DE JOS" UNIVERSITY OF GALATI

FASCICLE IX. METALLURGY AND MATERIALS SCIENCE

No. 1 - 2021, ISSN 2668-4748; e-ISSN 2668-4756

Article DOI: $\underline{\text { https://doi.org/10.35219/mms.2021.1.03 }}$

Table 2. Mechanical proprieties of the base materials [20,21]

\begin{tabular}{ccc}
\hline Properties & X2CrNiMo17-12-2 -Value & S235JR + AR - Value \\
\hline Yield strength $\left(\mathrm{R}_{\mathrm{p} 02}\right)$ & $170 \mathrm{~N} / \mathrm{mm}^{2}$ & Max. $235 \mathrm{~N} / \mathrm{mm}^{2}$ \\
Tensile Strength $\left(\mathrm{R}_{\mathrm{m}}\right)$ & $485 \mathrm{~N} / \mathrm{mm}^{2}$ & $360-510 \mathrm{~N} / \mathrm{mm}^{2}$ \\
Elongation $\left(\mathrm{A}_{5}\right)$ & $\min .40 \%$ & Max. $26 \%$ \\
\hline
\end{tabular}

As a result of the analysis, T $2312 \mathrm{~L} \mathrm{PC} \mathrm{/} \mathrm{M} 1$ is the best choice for making the dissimilar welded joints between carbon steel S235JR + AR and austenitic stainless steel X2CrNiMo17-12-2.
Subsequently, the chemical composition of the wire used, and the mechanical properties of the melt metal are presented in Table 3, respectively Table 4.

Table 3. Chemical composition of the filler material [22]

\begin{tabular}{cccccccccc}
\hline Chemical Composition & $\mathrm{C} \%$ & $\mathrm{Cr} \%$ & $\mathrm{Mn} \%$ & $\mathrm{Mo} \%$ & $\mathrm{~N} \%$ & $\mathrm{Ni} \%$ & $\mathrm{P} \%$ & $\mathrm{~S} \%$ & $\mathrm{Si} \%$ \\
\hline T 23 12 LPC/M 1 & 0.04 & 22.85 & 0.60 & 0.162 & 0.0266 & 12.54 & 0.019 & 0.009 & 0.65 \\
\hline
\end{tabular}

Table 4. Mechanical proprieties of the filler material [22]

\begin{tabular}{cc}
\hline Properties & T 2312 LPC/M 1-Value \\
\hline Yield strength $\left(\mathrm{R}_{\mathrm{p} 02}\right)$ & $460 \mathrm{~N} / \mathrm{mm}^{2}$ \\
Tensile Strength $\left(\mathrm{R}_{\mathrm{m}}\right)$ & $610 \mathrm{~N} / \mathrm{mm}^{2}$ \\
Elongation $\left(\mathrm{A}_{5}\right)$ & $\mathrm{min} .31 \%$ \\
\hline
\end{tabular}

\subsection{Welding process}

The MAG process was chosen using the M21 protection gas $\left(\mathrm{Ar}+18 \% \mathrm{CO}_{2}\right)$ for welding the samples. The parameters of the welding regime used in the experiments were determined in accordance with the manufacturer's recommendations.

The following steps were taken to prepare the welding samples:

- Plate cutting to size - The base materials prepared for the experiment are the steels: S235JR+AR and X2CrNiMo17-12-2 in form of plates with the dimensions $350 \mathrm{~mm} \times 225 \mathrm{~mm} \times 15 \mathrm{~mm}$. The cutting of the plates was performed using a Hypertherm Powermax 105 plasma cutting machine.
- The gripping of the parts for welding - The plates were fastened by using two steel plates, then placed on the welding table and subsequently the connecting to the table and to the welding source was made.

- The welding of the samples:

- Equipment used - a MIG / MAG TM 500 W

Welding Machine was used to perform samples using the MAG process. For measuring the temperature between the layers, a Voltacraft IR900-30S Thermometer was used.

- The welding - The welding of the samples was conducted with a ceramic root using the MAG process. The groove configuration presented in Figure 1.

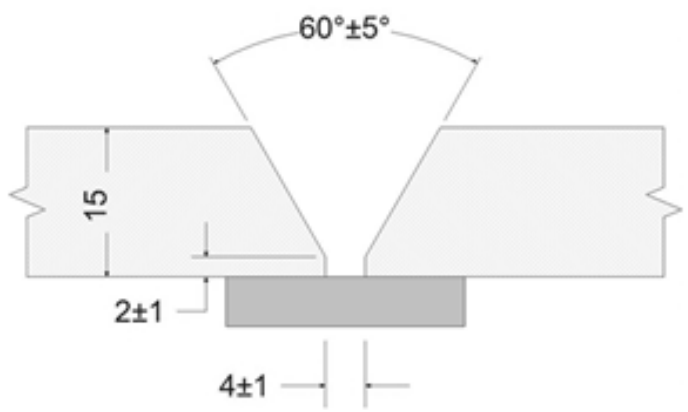

Fig. 1. The groove configuration and the positioning of the ceramic support 
The set parameters were monitored during the entire welding process, ascertaining differences of maximum $3 \mathrm{~A}$ for the amperage and $1 \mathrm{~V}$ for the welding arc. Table 5 .

Table 5. Welding parameters

\begin{tabular}{|c|c|c|c|c|}
\hline Welding parameter & $\begin{array}{l}\text { Values for the } \\
\text { root layer }\end{array}$ & \multicolumn{2}{|c|}{$\begin{array}{c}\text { Values for the intermediate } \\
\text { layers ( } 3 \text { layers) }\end{array}$} & $\begin{array}{l}\text { Values for the } \\
\text { surface layers }\end{array}$ \\
\hline Welding current, $\mathrm{I}_{\mathrm{s}}[\mathrm{A}]$ & $170 \pm 10$ & \multicolumn{2}{|c|}{$170 \pm 10$} & $170 \pm 10$ \\
\hline Welding arc voltage, $\mathrm{U}_{\mathrm{a}}[\mathrm{V}]$ & $29 \pm 2$ & \multicolumn{2}{|c|}{$29 \pm 2$} & $29 \pm 2$ \\
\hline Welding speed, $\mathrm{v}_{\mathrm{s}}[\mathrm{mm} / \mathrm{s}]$ & 1.71 & 2.14 & 1.79 & 4.8 \\
\hline $\begin{array}{l}\text { Feed rate of welding wire, } \\
\qquad v_{\mathrm{a}}[\mathrm{m} / \mathrm{min}]\end{array}$ & $4.8 \pm 0.1$ & \multicolumn{2}{|c|}{$4.8 \pm 0.1$} & $4.8 \pm 0.1$ \\
\hline $\begin{array}{c}\text { Gas flow }(\mathrm{Ar} 82 \%+18 \% \\
\left.\mathrm{CO}_{2}\right), \mathrm{D}_{\mathrm{g}}[1 / \mathrm{min}]\end{array}$ & $18 \pm 1$ & \multicolumn{2}{|c|}{$18 \pm 1$} & $18 \pm 1$ \\
\hline
\end{tabular}

\subsection{Non-destructive examination of the samples}

In order to analyse the quality of the welded joint obtained a series of non-destructive examination methods were used, after which specimens were taken to carry out the destructive tests.

In order to highlight any imperfections, present in the welded structure obtained, the sample was subjected to Visual Testing, Penetrant Testing, Ultrasound Testing and Radiographic Testing.

Visual inspection of the welded structure was performed using the direct viewing method.

\subsubsection{Dry Penetrant Testing}

In order to highlight the small imperfections on the surface of the test sample (which cannot be detected visually) or in the immediate vicinity of the surface, the test with penetrant liquid was used.

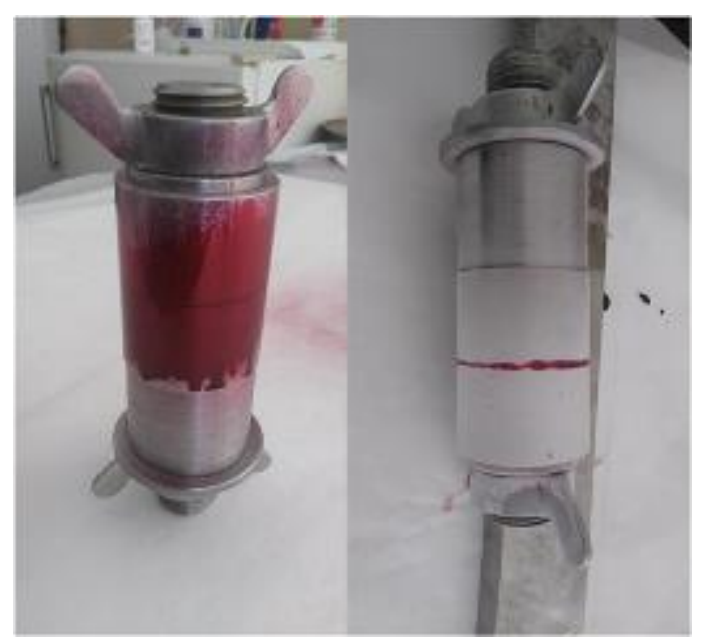

Fig. 2. Penetrant testing of the Miller etalon
For the examination using Penetrant Testing the following were established: ambient temperature: 20 ${ }^{\circ} \mathrm{C}$; set of penetrating liquids: penetrant PFINDER 860 type and developer PFINDER 870 type; calculation of geometric sensitivity using the Miller standard and penetration and development time: 10 $\min$.

For calculation of geometric sensitivity, the Miller etalon was used, see Figure 2. After the calculations, a geometric sensitivity of 0.965 was obtained.

Steps followed:

a) Sample cleaning - the sample was chemically cleansed by degreasing: PFINDER 890 degreaser.

b) Drying of the surface - forced by a hot air jet.

c) Applying the PFINDER 860 penetrant:

- The penetrant has been applied to the contact surface by spraying.

- Dwell time used: $10 \mathrm{~min}$.

d) Removing the excess of penetrant - the excess penetrant was removed by washing.

e) Surface drying - forced by a hot air jet.

f) Application of developer PFINDER 870:

- The developer was applied uniformly and thinly layer over the entire examined surface, only after being well agitated.

- After application of the developer, the surface examined was allowed to dry at room temperature.

- The development time begins immediately after surface drying; the development time was 10 minutes.

g) The interpretation of the results was achieved at the end of the development time.

- Upon examination with penetrating liquids, it was found that the piece had no detectable 


\section{THE ANNALS OF “DUNAREA DE JOS” UNIVERSITY OF GALATI \\ FASCICLE IX. METALLURGY AND MATERIALS SCIENCE \\ No. 1 - 2021, ISSN 2668-4748; e-ISSN 2668-4756 \\ Article DOI: https://doi.org/10.35219/mms.2021.1.03}

imperfections by this method on the surface under consideration.

The penetrant testing kit used it is presented in Figure 3, and the result obtained after the testing of the samples.

Upon examination with penetrating liquids, it was found that the piece had no detectable imperfections by this method on the surface under consideration.

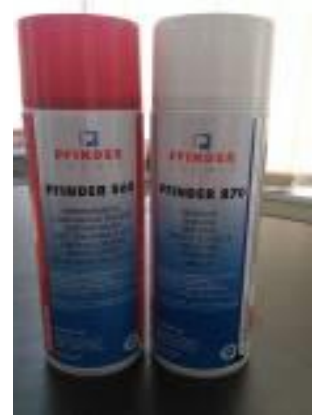

Fig. 3. Penetrant testing kit

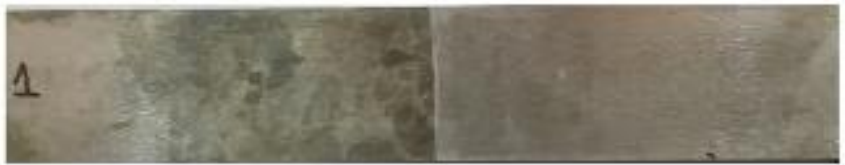

a)

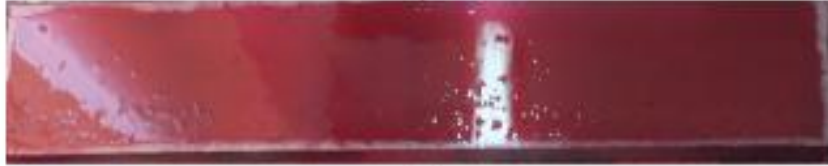

b)

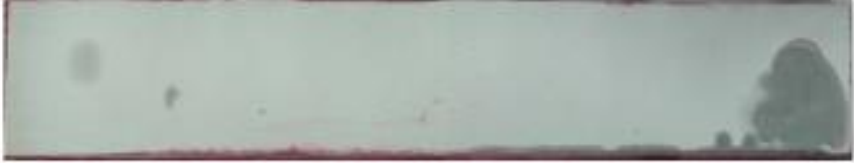

c)

Fig. 4. Penetrant testing of the samples: $a$ - test sample, $b$ - application of the penetrant layer; $c$ - the result obtained after drying by the developer

\subsubsection{Ultrasound Testing}

To perform the examination, an Olympus Defectoscope was used and two transducers with inclined incidence at the angles of $60^{\circ}$ and $70^{\circ}$.

To see if the chosen equipment and technique can be applied to the type of joint performed, a specimen was debited from the samples, in which imperfections with a diameter of $3 \mathrm{~mm}$ were formed at a depth of $6 \mathrm{~mm}$ on the edge of the welding seam, in cross-section. The experimental stand used for the ultrasound testing; the reflected pulse method is presented in Figure 5.

Subsequently the welded joints were subjected to ultrasound examination by the TOFD technique. In Figure 6 and 7 one of the TOFD report is presented.

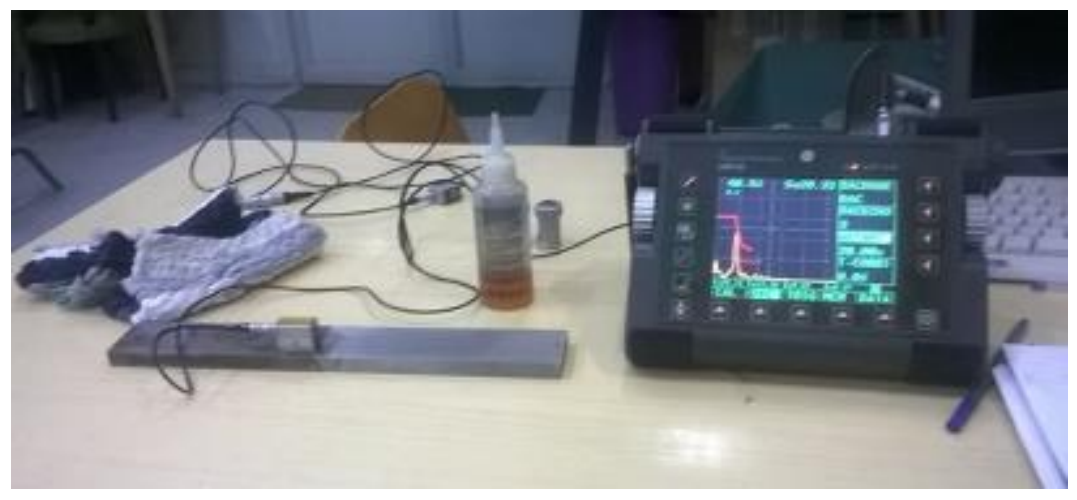

Fig. 5. Ultrasound testing of the samples 


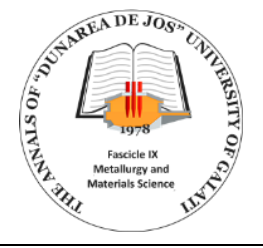

THE ANNALS OF "DUNAREA DE JOS" UNIVERSITY OF GALATI

FASCICLE IX. METALLURGY AND MATERIALS SCIENCE

$\mathrm{N}^{\circ} .1$ - 2021, ISSN 2668-4748; e-ISSN 2668-4756

Article DOI: https://doi.org/10.35219/mms.2021.1.03

\section{Ultrasound Report}

\begin{tabular}{|llllll|}
\hline Report Date & Report Version & Data File Name & Inspection Date & Inspection Version & Hardmare Type \\
$2016 / 05 / 12$ & OmmiscanConrerter - & PROBA $1=$ & $2016 / 05 / 11$ & ADXU - 3.1R3 & OMMT-M-UT-SC \\
\hline
\end{tabular}

Group 1

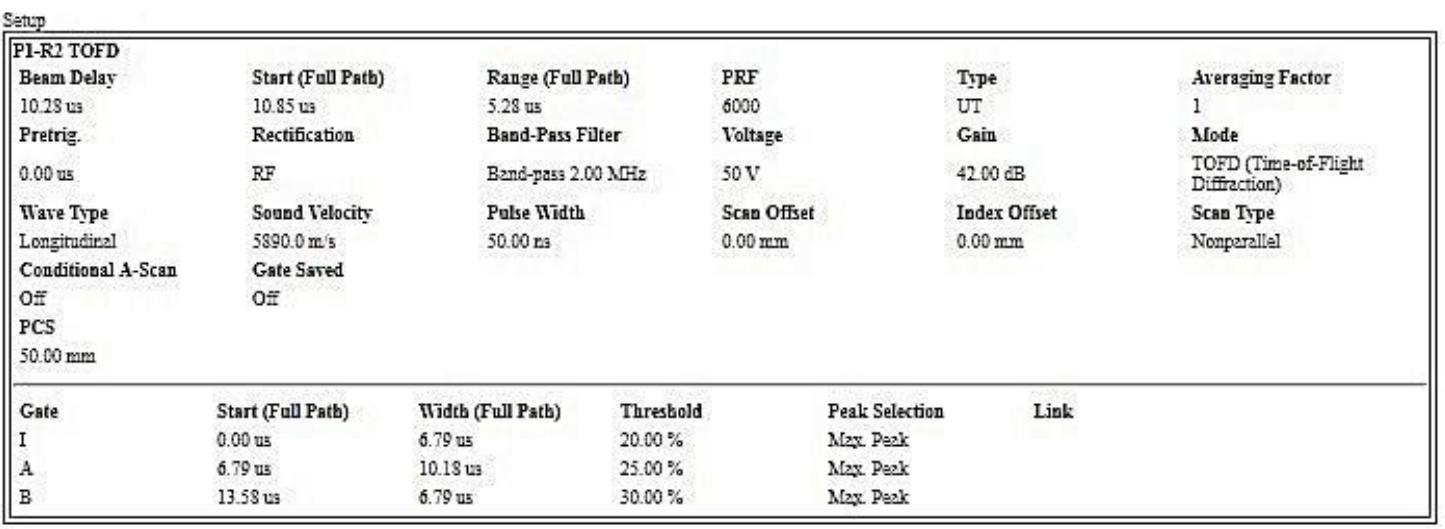

\begin{tabular}{|lll||}
\hline Pat & & \\
\hline SIaterial & Geometry & Thickness \\
STBEL, MIID & Plate & $15.00 \mathrm{~mm}$ \\
\hline
\end{tabular}

\begin{tabular}{|c|c|c|c|c|c|}
\hline \multicolumn{6}{|c|}{ San Area } \\
\hline Scan Start & Scru Lengtb & Scan Resolution & Index Start & Index Levgth & Index Resolution \\
\hline $0.00 \mathrm{~mm}$ & $280.00 \mathrm{~mm}$ & $1.00 \mathrm{~mm}$ & $0.00 \mathrm{~mm}$ & $0.00 \mathrm{~mm}$ & $1.00 \mathrm{~mm}$ \\
\hline Syachro & Max. Scan Speed & & & & \\
\hline Encoder & $6000.00 \mathrm{~mm} / \mathrm{s}$ & & & & \\
\hline Axis & Encoder & Encoder Type & Encoder Resolution & Polarity & \\
\hline Son & 1 & Quadrature & 12.00 step mm & Normal & \\
\hline Index & OIf & OIf & OIf & Off & \\
\hline
\end{tabular}

Fig. 6. TOFD parameters

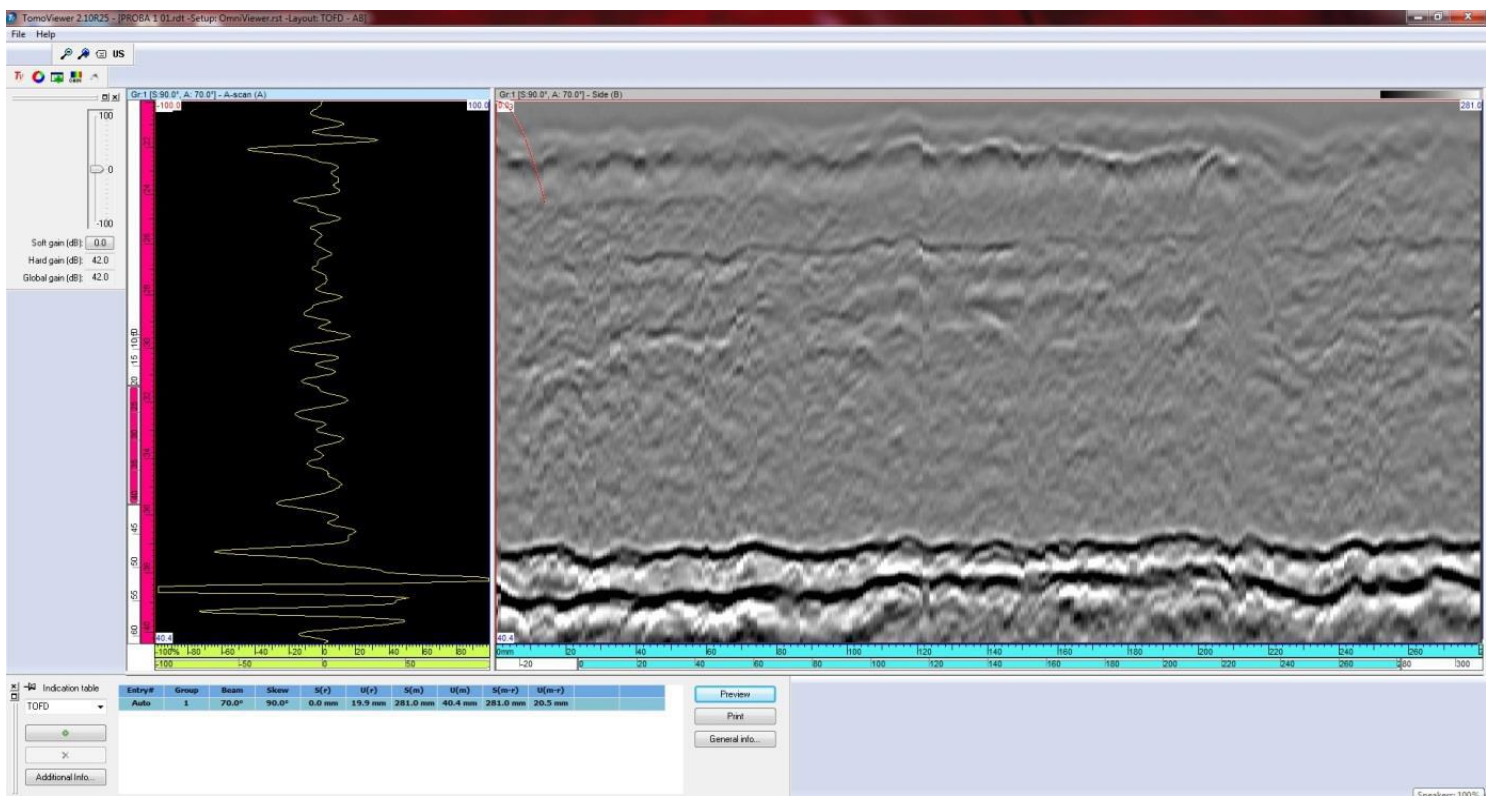

Fig. 7. TOFD report results 


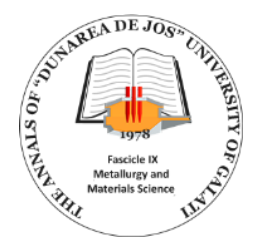

THE ANNALS OF “DUNAREA DE JOS” UNIVERSITY OF GALATI

FASCICLE IX. METALLURGY AND MATERIALS SCIENCE

No. 1 - 2021, ISSN 2668-4748; e-ISSN 2668-4756

Article DOI: $\underline{\text { https://doi.org/10.35219/mms.2021.1.03 }}$

\subsubsection{Radiographic Testing}

Due to the fact that after the ultrasound examination the results were inconclusive, the samples were subsequently examined by Radiographic Testing.

The examination of the steel samples was carried out with the help of the X-ray non-destructive testing, obtaining the image on a radiographic film.

Technical data:

- Sample: dissimilar welded joint sheet between carbon steel and austenitic stainless steel.

- Material: steels S235JR and X2CrNiMo17-122.

- Dimensions: thickness $12 \mathrm{~mm}$, length $350 \mathrm{~mm}$, width $450 \mathrm{~mm}$.
- Exposure geometry: Normal geometry.

- Radiography technique: a wall.

- Radiography class: Class B

- Radiographic parameters:

- a X-ray tube parameters: $\mathrm{U}=150 \mathrm{KV} ; \mathrm{I}=4.5$ $\mathrm{mA}$;

- a source-film distance $=500 \mathrm{~mm}$;

- an exposure time $=1$ minute and 30 seconds .

- Quality indicators used: Group $1 \mathrm{H} \mathrm{Fe}$ with the following hole diameters: Visible $\mathrm{H} 4$

- Film FOMAPAK
FULIC, EU (R5 + Pb).

- Very high blackness density $=3$.

- Image blur index = the number of the largest perceptible element.

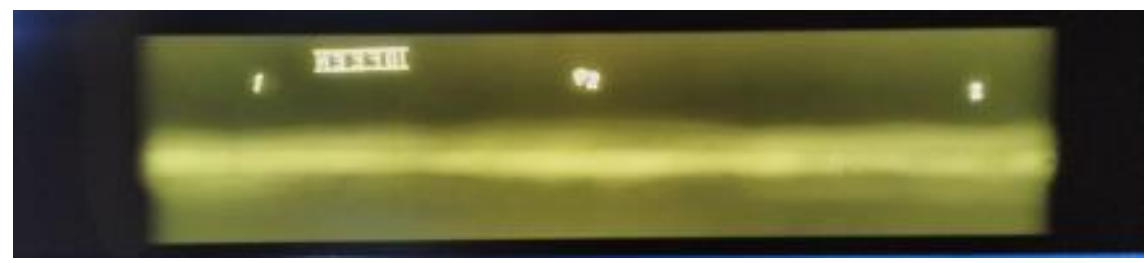

Fig. 8. Radiographic film-sample 2

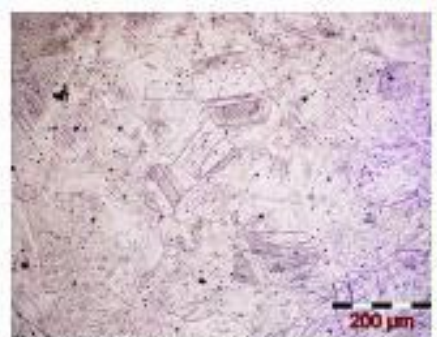

a) $\mathrm{X} 2 \mathrm{CrNiMo17-12-2} \mathrm{microstructure}$

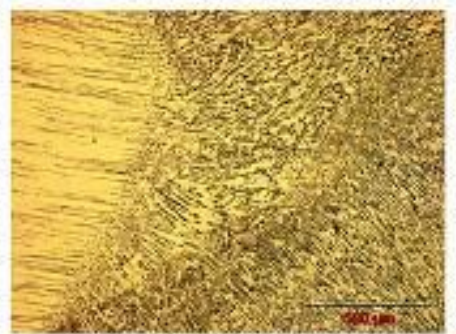

b) heut affected zone near X2CrNiMol 7-12-2

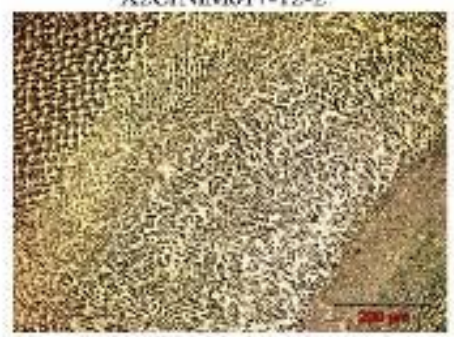

d) welded seam

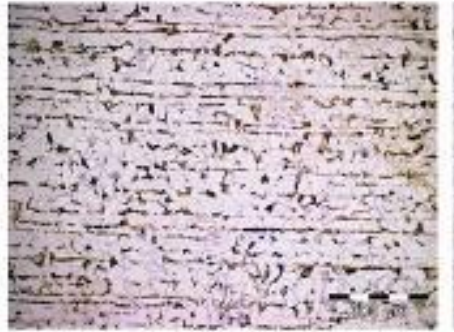

c) $\$ 235 \mathrm{IR}+\mathrm{AR}$ microstructure

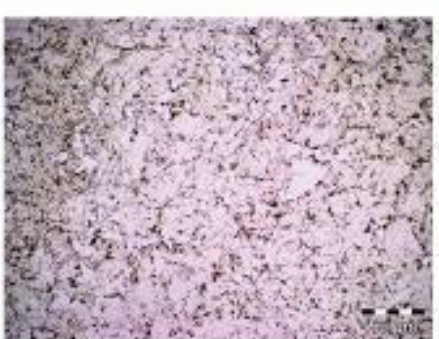

f) heat affected zone near $\$ 235 \mathrm{JR}$ $A R$

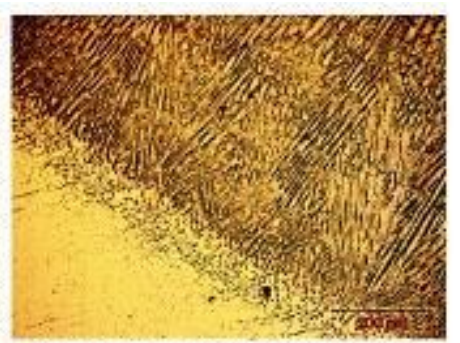

c) fusion line - $\mathrm{X}_{2} \mathrm{CrNiM}$ 1 7-12-2

Fig. 9. Microscopic analysis

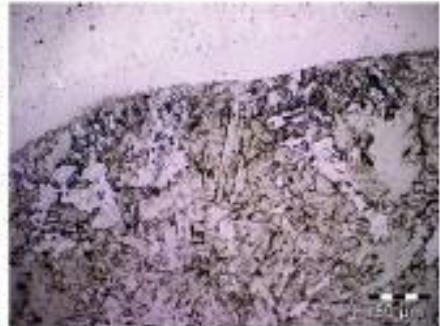

8) fusion line $-\$ 235 \pi R+A R$ 
There were no imperfections of the interior highlighted using the Radiographic Testing, result which attest to the quality of the welded joint, as it can be seen from Figure 8 .

In order to analyse the microstructure obtained destructive examination was applied. In figure 9 is presented the microstructure obtained in the areas of interest, namely: the heat-affected area, the fusion line, and the welded seam.

After analysing the microscopic images obtained the differences in structure can be seen, as follows:

- Stainless steel, X2CrNiMo17-12-2, shows microstructure with snail polyhedron grains and intragranular precipitations.

- Carbon steel, S235JR + AR, presents a ferriteperlite microstructure in alternating ferrite and perlite strings.

- The fusion line between carbon steel, S235JR $+\mathrm{AR}$ (lower part), and deposition by welding with a high alloyed material (top). The HAZ shows the tendency to increase the granulation and the formation of the perlite and the coarse ferrite Widmanstätten type.

- The fusion line between austenitic stainless steel, X2CrNiMo17-12-2, and welding with a high alloyed material. One biphasic ferrite and austenitic dendritic microstructure can be observed.

- In the heat affected zone near S235JR + AR a modified ferrite and perlite structure is observed.

- In the heat affected zone near X2CrNiMo1712-2 a dendritic microstructure directed towards the direction of the thermal delta and austenite ferrite flow is observed.

- The welded seam shows a dendritic structure of delta and austenite ferrite.

\section{Conclusions}

From the analysis of the presented, important conclusions are drawn as follows:

- Dissimilar welded samples using the MAG welding process were created.

- After the welding process the samples were non - destructively tested.

- No imperfections have been identified following Visual Testing and Penetrant Testing.

- The result obtained using Ultrasound Testing, through the two methods of welded samples was inconclusive, due to the difference in structure between the two basic materials.

- Ultrasonic examination of austenitic stainless steel is difficult because of the grain size. Due to the fact that the austenitic stainless steel presents a coarse structure in case of ultrasound testing the grain boundary sometimes can be mistaken as a flow by the equipment. On the screen of the ultrasound defectoscope a sonic grass can be observed which can mask small imperfections making them impossible to detect.

- The examination with Radiographic Testing confirmed the lack of imperfections in the welded samples.

\section{Acknowledgment}

This work has been funded by the European Social Fund from the Sectoral Operational Programme Human Capital 2014-2020, through the Financial Agreement with the title "Scholarships for entrepreneurial education among doctoral students and postdoctoral researchers (Be Antreprenor!)", Contract no. 51680/09.07.2019 - SMIS code: 124539.

\section{References}

[1]. Baldev Raj, Subramanian C. V., Jayakumar T., NonDestructive Testing of Welds, Alpha Science International, Limited, 2001.

[2]. Paul Kah, Belinga Mvola, Jukka Martikainen, Raimo Suoranta, Real Time Non-Destructive Testing Methods of Welding, Advanced Materials Research, vol. 933, p. 109-116, https://doi.org/10.4028/www.scientific.net/AMR.933.109, 2014.

[3]. Baughurst L., Voznaks G., Welding defects, causes and correction, Australian Bulk Handling Review, http://courseware.cutm.ac.in/wp-

content/uploads/2020/06/welding_defects_causes_correction.pdf, July/August 2009.

[4]. Oral Büyüköztürk, Mehmet Ali Tașdemir, Nondestructive Testing of Materials and Structures, Springer Science \& Business Media, 2012.

[5]. Scutelnicu E., Constantin E., Heat input influence on structural changes in carbon steel - stainless steel welded joints, Proceedings of the $10^{\text {th }}$ International Metallurgy and Materials Congress, ISSN 1301-3637, Istanbul, Turkey, vol. II, p. 1239-1244, 24-28 May 2000.

[6]. Taban E., Deleu E., Dhooge A., Kaluc E., Evaluation of dissimilar welds between ferritic stainless steel modified $12 \% \mathrm{Cr}$ and carbon steel S355, Weld. J., 87, p. 291-297, 2008.

[7]. Dijmărescu Maria-Cristina, Dijmărescu Manuela-Roxana, Welding Material Selection for a Specific Butt V-Weld by Means of Assisted Stress and Fatigue Calculations, ISMEMS 2016, Advances in Engineering Research, vol. 93, Atlantic Press, p. 6166, 2016.

[8]. Mvola B., Kah P., Martikainen J., Dissimilar ferrous metal welding using advanced gas metal arc welding processes, Rev. Adv. Mater. Sci., 38, p. 125-137, 2014.

[9]. Tasalloti H., Kah P., Martikainen J., Effect of heat input on dissimilar welds of ultra high strength steel and duplex stainless steel: Microstructural and compositional analysis, Mater. Charact., 123, p. 29-41, DOI: doi.org/10.1016/j.matchar.2016.11.014, 2017.

[10]. Ghosh N., Kumar Pal P., Nandi G., GMAW dissimilar welding of AISI 409 ferritic stainless steel to AISI 316L austenitic stainless steel by using AISI 308 filler wire, Eng. Sci. Technol., 20, p. 1334-1341, DOI: doi.org/10.1016/j.jestch.2017.08.002, 2017.

[11]. Jing W., Min-Xu L., Lei Z., Wei C., Ningxu L., Li-Hua H., Effect of welding process on the microstructure and properties of dissimilar weld joints between low alloy steel and duplex stainless steel, Int. J. Min. Met. Mater., 19 (6), p. 518-524, DOI: 10.1007/s12613-012-0589-z, 2012.

[12]. Mirsalehi S. E., Ahmadi M., Investigation on microstructure, mechanical properties and corrosion behavior of AISI 316L stainless steel to ASTM A335-P11 low alloy steel 


\section{THE ANNALS OF “DUNAREA DE JOS" UNIVERSITY OF GALATI \\ FASCICLE IX. METALLURGY AND MATERIALS SCIENCE \\ $\mathrm{N}^{\circ} .1$ - 2021, ISSN 2668-4748; e-ISSN 2668-4756 \\ Article DOI: https://doi.org/10.35219/mms.2021.1.03}

dissimilar welding joints, Mater. High Temp., 32, p. 627-635, DOI: doi.org/10.1179/1878641315Y.0000000009, 2015.

[13]. Dev S., Devendranath Ramkumar K., Arivazhagan N., Rajendran R., Investigations on the microstructure and mechanical properties of dissimilar welds of inconel 718 and sulphur rich martensitic stainless steel, AISI 416, J. Manuf. Process., 32, p. 685-698, 2018.

[14]. Kurt A., Uygur I., Paylasan U., Effect of friction welding parameters on mechanical and microstructural properties of dissimilar AISI 1010-ASTM B22 joints, Welding Journal, 90 (5), p. 102-106, 2011.

[15]. Albert S. K., Das C. R., Shiju S., Mastanaiah P., Patel M., Bhaduri A. K., Jayakumar T., Murthy C. V. S., Rajendra K. Mechanical properties of similar and dissimilar weldments of RAFMS and AISI 316L (N) SS prepared by electron beam welding process, Fusion Eng. Des., 89, p. 1605-1610, DOI: doi.org/10.1016/j.fusengdes.2014.04.063, 2014.

[16]. Di H., Sun Q., Wang X., Li J., Microstructure and proprieties in dissimilar/ similar weld joints between DP780 and
DP980 steels processed by fiber laser welding, J. Mat. Sci. Technol., 33, p. 1561-1571, 2017.

[17]. ***, Non-destructive Testing, classification notes No. 7, Det Norske Veritas AS, March 2012.

[18]. Halmshaw R., Introduction to the Non-Destructive Testing of Welded Joints, Second Edition, Abington Publishing, 2006.

[19]. Oral Büyüköztürk, Mehmet Ali Taşdemir, Nondestructive Testing of Materials and Structures, Springer Science \& Business Media, 2012.

[20]. ***, SR EN 10025 - 2 - Hot rolled products of structural steels - Part 2: Technical conditions for non-alloy structural steels, 2004.

[21]. ***, SR EN 10088-2 - Stainless steels - Part 2: Technical delivery conditions for sheet/plate and strip of corrosion resisting steels for general purposes, 2015.

[22]. ***, SR EN ISO 17633-A - Welding consumables - Tubular cored electrodes and rods for gas shielded and non-gas shielded metal arc welding of stainless and heat-resisting steels Classification, 2010. 